Fifth International Conference on Sustainable Construction Materials and

Technologies. http://www.claisse.info/Proceedings.htm

\title{
PERFORMANCE OF NANO-MODIFIED CONCRETE UNDER FREEZING AND LOW TEMPERATURES
}

\author{
A. Yasien ${ }^{1}$, A. Abayou ${ }^{2}$ and M. T. Bassuoni ${ }^{3 *}$ \\ ${ }^{1} \mathrm{PhD}$. Candidate, Civil Engineering, University of Manitoba, Winnipeg, Canada \\ ${ }^{2}$ MSc. Candidate, Civil Engineering, University of Manitoba, Winnipeg, Canada \\ ${ }^{3 *}$ Associate Professor, Civil Engineering, University of Manitoba, Winnipeg, Canada (Corresponding \\ Author)
}

\begin{abstract}
In this study four mixtures were prepared at a constant $w / b$ of 0.32 with different combinations of general use cement, Class F fly ash and nano-silica sol, targeting applications in cold weather. All mixtures incorporated calcium nitrate-nitrite solution as an antifreeze admixture. The mixtures were mixed, cast and cured using two different regimes: a constant freezing temperature of $-5^{\circ} \mathrm{C}$, and cyclic freezing-low temperatures $\left(-5 / 5^{\circ} \mathrm{C}\right)$, without heating or insulation during the curing period. The performance of mixtures was assessed by setting time, compressive strength and mercury intrusion porosimetry tests. In addition, scanning electron microscopy was performed to characterize the microstructure of concrete. The incorporation of nanosilica significantly enhanced the overall performance of concrete, even with fly ash, indicating its promising use for cold weather applications in late fall and early spring periods, without the need for conventional heating and insulation practices.
\end{abstract}

Keywords: Fly Ash, Nano-Silica, Concrete, Freezing/Low Temperatures, Sustainability

\section{INTRODUCTION}

Cold weather concreting is one of the most challenging problems that face concrete practitioners in cold regions. According to ACI 306R (2016) and CSA A23.1/A23.2 (2014), cold weather is when air temperature has fallen or expected to fall below 4 or $5^{\circ} \mathrm{C}$ during the mixing, casting and protection periods which are required for concrete to achieve mechanical and physical properties that can resist the effect of being exposed to such harsh conditions. Under low temperatures (e.g. $\left.5^{\circ} \mathrm{C}\right)$, the hydration progress slows down significantly, and it completely stops when the curing temperature goes below $0^{\circ} \mathrm{C}$ leading to freezing of approximately $95 \%$ of the mixing water (Neville, 2011; Ratinov and Rozenberg, 1996). This limits the concrete strength development and induces micro- and macro-cracks in the matrix at early-ages.

In USA and Canada, both ACI 306R (2016) and CSA A23.1-A23.2 (2014) direct concrete practitioners to use conventional techniques such as heating up concrete ingredients (fine and coarse aggregates and water), and using enclosures to warm up the surrounding environment to provide favorable curing conditions for concrete. 
These practices entail significant costs due to the requirements of energy consumption, enclosure materials, and quality control by skilled manpower. The required cost to thermally protect concrete during construction from freezing has been recently estimated at one billion dollars per year (Barna et al., 2011). Therefore, in cold regions, construction seasons of concrete infrastructure are typically limited to five months (from May to September) leading to busy construction summer periods, delay in repair schedules and significant socioeconomic losses. Hence, there is urgent need to find innovative techniques and strategies to prolong the construction season in cold climates.

The incorporation of cold weather admixture systems (CWAS) in concrete to mitigate challenges of cold weather concreting has been introduced since 1950s. These systems can depress the freezing point of the mixing water, accelerate the cement hydration rate, and expedite concrete strength development (Polat, 2016; Karagol et al., 2013). However, their effects on the durability of concrete might be adverse by developing coarse/continuous pore structure.

Nanoparticles (e.g. nano-silica) have attracted considerable interest in concrete research in the past decade. Their ultrafine nature significantly affects the mechanical and physical properties of concrete (Haruehansapong et al., 2014; Ghazy et al., 2016; Said et al., 2012). Nano-silica can accelerate the cement hydration process, efficiently refine the pore structure of cementitious matrices and densify the interfacial transition zone (ITZ) between aggregates and cement paste (Ghazy et al., 2016; Said et al., 2012). However, there is still lack of information about its effect and reactivity under low and sub-zero temperatures. In additions, research is still needed on aspects such as the interaction between CWAS and nano-silica to produce concrete mixtures suitable for cold weather applications with satisfactory placement, mechanical and durability properties.

Based on the aforementioned research needs and gaps, the scope of this study is to investigate the interaction of CWAS and nano-silica to produce concrete mixtures that can be cast and cured at freezing temperatures $\left(-5^{\circ} \mathrm{C}\right)$ and cyclic freezing-low temperatures $\left(-5 / 5{ }^{\circ} \mathrm{C}\right)$ without any method of protection. These regimes cover the average minimum temperatures of the late fall (October to November) and early spring (March to April) periods in many geographic locations in North America and Europe. In addition, a blended binder containing $25 \%$ fly ash, which is not recommended for cold weather application according to ACI 306R (2016), had been evaluated in this study. The fresh and hardened properties of the concrete mixtures were investigated, and the trends were corroborated by scanning electron microscopy analysis.

\section{EXPERIMENTAL PROCEDURE}

\section{Materials}

General use portland cement (GU) and fly ash (Class F), which meet the requirements of CAN/CSA-A3001 (2013) were used as the main binder components. Moreover, a commercial solution of nano-silica $\left[50 \%\right.$ solid content of $\mathrm{SiO}_{2}$ dispersed in water based 
solution] was incorporated in some mixtures as partial replacement of cement by mass. The chemical and physical properties for the aforementioned materials are shown in Table 1. Well-graded river sand with fineness modulus of 2.9 and locally available natural gravel with maximum size of $9.5 \mathrm{~mm}$ were used. The specific gravity and absorption are 2.65 and $2 \%$, respectively for gravel, and 2.53 and $1.5 \%$, respectively for sand. The target slump range of the mixtures was $175 \pm 25 \mathrm{~mm}$ using a high-range water reducing admixture (HRWRA) based on polycarboxylic acid complying with ASTM C494 (2015), Type F. In addition, $6 \pm 1 \%$ air content of the different mixtures was achieved by incorporating an air-entraining admixture, complying with ASTM C260/C260M (2016). A combination (CNAI) of calcium nitrite (CNI) and calcium nitrate (CNA) with 1:1 mass ratio (Table 2), which proved to be an efficient antifreeze and accelerating admixture (Karagol et al., 2013; Ratinov and Rozenberg, 1996), was incorporated in all mixtures at a constant dosage of $15 \%$ by mass of mixing water. This concentration has been conservatively selected based on the phase diagram of CNAI (Figure 1) to depress the freezing point of mixing water down to the curing temperature $\left(-5^{\circ} \mathrm{C}\right)$ and account for uncertainties of lower temperatures in the field.

Table 1: Chemical and physical properties of cement, fly ash and nano-silica

\begin{tabular}{c|c|c|c}
\hline & GU cement & Fly ash & Nano-silica \\
\hline $\mathrm{SiO}_{2}(\%)$ & 19.8 & 56.0 & 99.17 \\
\hline $\mathrm{Al}_{2} \mathrm{O}_{3}(\%)$ & 5 & 23.1 & 0.38 \\
\hline $\mathrm{Fe}_{2} \mathrm{O}_{3}(\%)$ & 2.4 & 3.6 & 0.02 \\
\hline $\mathrm{CaO}(\%)$ & 63.2 & 10.8 & -- \\
\hline $\mathrm{MgO}(\%)$ & 3.3 & 1.1 & 0.21 \\
\hline $\mathrm{SO}_{3}(\%)$ & 3 & 0.2 & -- \\
\hline $\mathrm{Na}_{2} \mathrm{O}_{\text {eq. }}(\%)$ & 0.6 & 3.1 & 0.20 \\
\hline $\mathrm{Specific} \mathrm{gravity}$ & 3.15 & 2.12 & 1.4 \\
\hline $\mathrm{Mean}$ particle size, & 13.15 & 16.56 & $35 \times 10^{-3}$ \\
$\mu \mathrm{m}$ & $390^{*}$ & $290^{*}$ & $80,000^{\dagger}$ \\
\hline Fineness, $\mathrm{m}^{2} / \mathrm{kg}$ & -- & -- & 8 \\
\hline Viscosity, Cp & -- & -- & 9.5 \\
\hline pH & & &
\end{tabular}

*Blaine fineness.

${ }^{\dagger}$ Fineness was determined by titration with sodium hydroxide according to the

manufacturer.

\section{Procedures}

The nano-silica and fly ash were incorporated at constant dosages of $4 \%$ and $25 \%$ replacement by mass of cement $\left[400 \mathrm{~kg} / \mathrm{m}^{3}\right]$, respectively. These dosages proved to produce concrete with the desired fresh and hardened properties based on previous studies (e.g. Ghazy et al, 2016). Moreover, all mixtures had constant water-to-binder 
ratio $(w / b)$ of 0.32 . The proportions of the four mixtures tested in this study are shown in Table 3. Each mixture ID starts with letters denoting the binder type, cement (GU), fly ash (FA), nano-silica (NS) and/or combination of fly ash and nano-silica (FN), and subsequent numbers indicating the curing regimes: -5 for $-5^{\circ} \mathrm{C}$ and 5 for the cyclic regime $\left(5 /-5^{\circ} \mathrm{C}\right)$.

Table 2: Properties of calcium nitrate and calcium nitrite

\begin{tabular}{c|c|c}
\hline & Calcium nitrate & Calcium nitrite \\
\hline Specific gravity & 1.86 & 2.26 \\
\hline Sulfate & $0.01 \% \max$. & -- \\
\hline Chloride & $0.01 \%$ max. & -- \\
\hline $\begin{array}{c}\text { Molecular Weight, } \\
\text { g/mol }\end{array}$ & 236.15 & 132.09 \\
\hline $\begin{array}{c}\text { Solubility in water, g/l } \\
\text { at } 0{ }^{\circ} \mathrm{C}\end{array}$ & 1470 & $\begin{array}{c}\text { freely soluble in } \\
\text { water }\end{array}$ \\
\hline $\mathrm{pH}$ & 7 & 10 \\
\hline
\end{tabular}

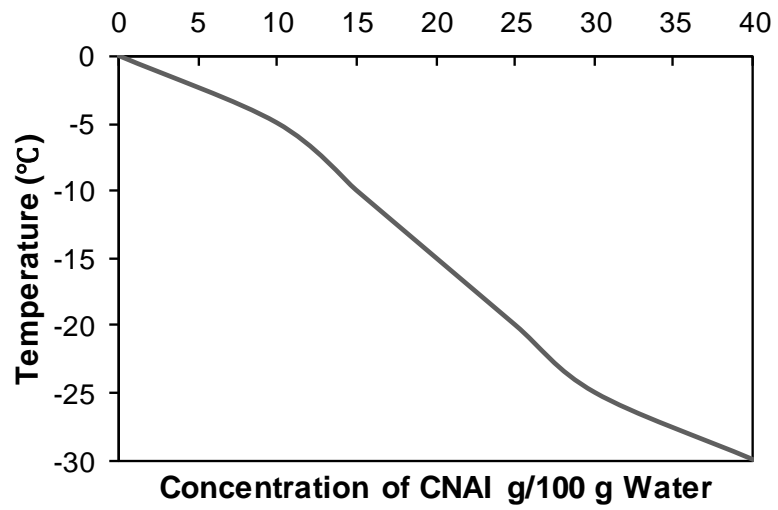

Figure 1: Calcium nitrate-nitrite (CNAI) phase diagram down to $-30^{\circ} \mathrm{C}$.

Table 3: Proportions of concrete mixtures per cubic meter

\begin{tabular}{c|c|c|c|c|c|c|c}
\hline $\begin{array}{c}\text { Mixture } \\
\text { ID }\end{array}$ & $\begin{array}{c}\text { Cement } \\
(\mathrm{kg})\end{array}$ & $\begin{array}{c}\text { Fly } \\
\text { ash } \\
(\mathrm{kg})\end{array}$ & $\begin{array}{c}\text { Nano } \\
- \text {-silica } \\
(\mathrm{kg})\end{array}$ & $\begin{array}{c}\text { CNA+CNI* } \\
(\mathrm{kg})\end{array}$ & $\begin{array}{c}\text { Water }^{\dagger} \\
(\mathrm{kg})\end{array}$ & $\begin{array}{c}\text { Fine } \\
\text { aggregate } \\
(\mathrm{kg})\end{array}$ & $\begin{array}{c}\text { Coarse } \\
\text { aggregate } \\
(\mathrm{kg})\end{array}$ \\
\hline GU5,-5 & 400 & 0 & 0 & $9.6+32$ & 105.6 & 622 & 1156 \\
\hline FA5,-5 & 300 & 100 & 0 & $9.6+32$ & 105.6 & 610 & 1133 \\
\hline NS5,-5 & 384 & 0 & 32 & $9.6+32$ & 89.6 & 621 & 1153 \\
\hline FN5,-5 & 284 & 100 & 32 & $9.6+32$ & 89.6 & 608 & 1129 \\
\hline
\end{tabular}

*The CNA and CNI admixtures are in solid and liquid forms, respectively.

*The CNA admixture is in solid form with $70 \%$ active ingredient.

${ }^{\dagger}$ Adjusted amount of water considering the water content of nano-silica (aqueous solution with $50 \%$ solid content of $\mathrm{SiO}_{2}$ ) and $\mathrm{CNI}$ (aqueous solution with $30 \%$ solid content). 
Mixing, casting and curing procedures were performed in an environmental chamber to simulate the two weather regimes adopted in this study: a constant temperature of $5^{\circ} \mathrm{C}$ and cyclic temperatures $\left(16 \mathrm{~h}\right.$ at $-5^{\circ} \mathrm{C}$ and $8 \mathrm{~h}$ at $\left.5^{\circ} \mathrm{C}\right)$. These regimes were selected based on the temperature history of the late-fall and early-spring of Manitoba, Canada. A specific sequence of mixing was adopted in this study based on trial batches. Constituent materials were mixed using a stationary drill mixer. The liquid admixtures (air-entrainer, HRWRA) and the nano-silica were added to $2 / 3$ of the mixing water (solution A) while the CNAI was added to the remaining $1 / 3$ of the mixing water (solution B). Firstly, both solutions A and B were stirred vigorously for 45 seconds. Afterwards, half of solution A was added to the aggregates and mixed together for 30 seconds. Subsequently, the cement and fly ash were added to the aggregates and mixed together for another 30 seconds. The remaining amount of solution A was added to the mixer pan and mixing continued for another $30 \mathrm{~s}$. Finally, solution B was added to the mixture and mixing continued for 3 min. After pouring concrete in moulds, a vibrating table $(60 \mathrm{~Hz})$ was used until air bubbles stopped appearing at the surface. To simulate the worst case scenario in the field, the specimens were kept in the environmental chamber without any protection/cover and subjected to a circulating air flow (20 to 30 $\mathrm{km} / \mathrm{h}$ ). After $24 \mathrm{~h}$, the specimens were demoulded and left in the chamber at these curing temperatures and windy conditions until testing.

\section{Testing Methods}

The initial and final setting times were determined based on the penetration resistance of the mortar fraction of each mixture [portion passing sieve \#4 $(4.75 \mathrm{~mm})$ ] which was placed in a container at $-5^{\circ} \mathrm{C}$ (worst curing temperature). The penetration resistance was determined by standard needles at specific time intervals according to ASTM C403 (2016). Moreover, for each mixture, three concrete cylinders with dimensions of $100 \times 200 \mathrm{~mm}$ were prepared to determine the 28 days compressive strength according to ASTM C39 (2018). In addition, to assess the characteristics of pore structure, the mercury intrusion porosimetry (MIP) test was conducted on concrete samples at 28 days. In addition, backscattered scanning electron microscopy (BSEM) analysis was performed on polished thin sections from the concrete mixtures to corroborate the trends obtained from the bulk tests. Slices were cut out from specimens, which were then dried and impregnated by a low-viscosity epoxy resin under vacuum pressure and polished by successive diamond surface-grinding to a thickness of 30 to $50 \mu \mathrm{m}$. Thereafter, these sections were carbon coated to enhance the conductivity for the BSEM analysis, assisted with elemental disperse X-ray (EDX).

\section{RESULTS AND DISCUSSION}

\section{Setting Time}

ASTM C403 (2016) stipulates a penetration resistance of 3.5 and $27.6 \mathrm{MPa}$ to reach both initial and final setting times, respectively. The setting time, for both curing regimes, was assessed based on a constant curing temperature of $-5^{\circ} \mathrm{C}$ to simulate the worst case scenario in the field. As depicted in Figure 2, the incorporation of either fly ash or nano-silica in the mixtures affected the rigidity behavior of concrete at $-5^{\circ} \mathrm{C}$, which varied between 3.7 to $7.2 \mathrm{~h}$. 


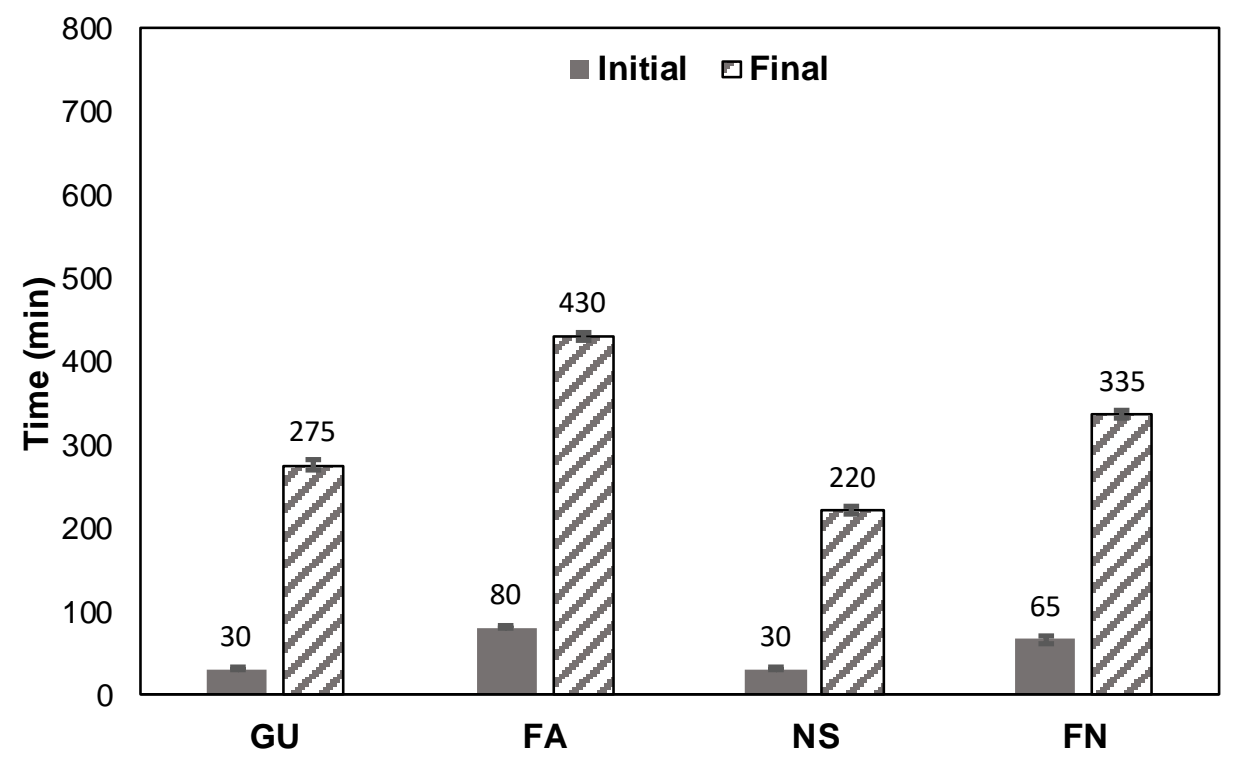

Figure 2: Initial and final setting times of the mixtures at $-5^{\circ} \mathrm{C}$. (Note: error bars represent standard deviation)

Generally, the addition of fly ash relatively prolonged both setting times of concrete compared to concrete without fly ash. For example, mixtures FA had 167\% and 56\% longer initial and final setting times, respectively relative to that of mixtures GU. The effect of incorporating higher dosages of fly ash (more than 20\%) in concrete on retarding the setting times of concrete cast and cured under normal temperatures is well-documented (Neville, 2011; Wesche, 2014). This is attributed to the dilution of cement with high dosage of fly ash which is less reactive supplementary cementitious material (SCM) due to the lower lime content, leading to delaying the kinetics of hydration and slower hardening rate, even with the incorporation of accelerators such as CNAI.

The incorporation of nano-silica in concrete significantly shortened the final setting time compared to other mixtures, without nano-silica. For instance, the initial and final setting times of nano-modified fly ash mixture FN were shortened by 15 and $95 \mathrm{~min}$, respectively compared to the mixtures incorporating fly ash only (FA). At normal temperatures, previous studies (Senff et al., 2009; Hou et al., 2013) proved the capability of nano-silica to accelerate the hydration process and calcium hydroxide $(\mathrm{CH})$ formation in cementitious systems at early-age. Nano-silica, which has very high surface area, act as nucleation sites for the hydration products to precipitate resulting in speeding up the dissolution of calcium silicate phases (Senff et al., 2009; Hou et al., 2013); consequently, it increases the production of $\mathrm{CH}$ and subsequently the pozzloanic activity in the matrix. It is worth noting that the hardening times of nano-modified and nano-modified fly ash mixtures (approximately 3.7 and $5.6 \mathrm{~h}$ ) are close to the setting times of nano-modified and nano-modified fly ash concrete mixtures cast and cured under normal conditions (Ghazy et al., 2016). Thus, the setting time trends from this study suggested that addition of nano-silica accelerated the hydration and solidification processes, as the inclusion of CNAI was effective at depressing the freezing point of 
liquid phases, which maintained the functionality of nano-silica at a freezing temperature.

\section{Compressive Strength}

The average compressive strengths of concrete cylinders from all mixtures after 28 days of curing under the aforementioned regimes are shown in Figure 3. The incorporation of both fly ash and nano-silica affected strength development in both curing regimes. The compressive strength ranged between 24 to $50 \mathrm{MPa}$ and 18 to 39 $\mathrm{MPa}$ for the $5 /-5^{\circ} \mathrm{C}$ and $-5^{\circ} \mathrm{C}$ curing regimes, respectively.

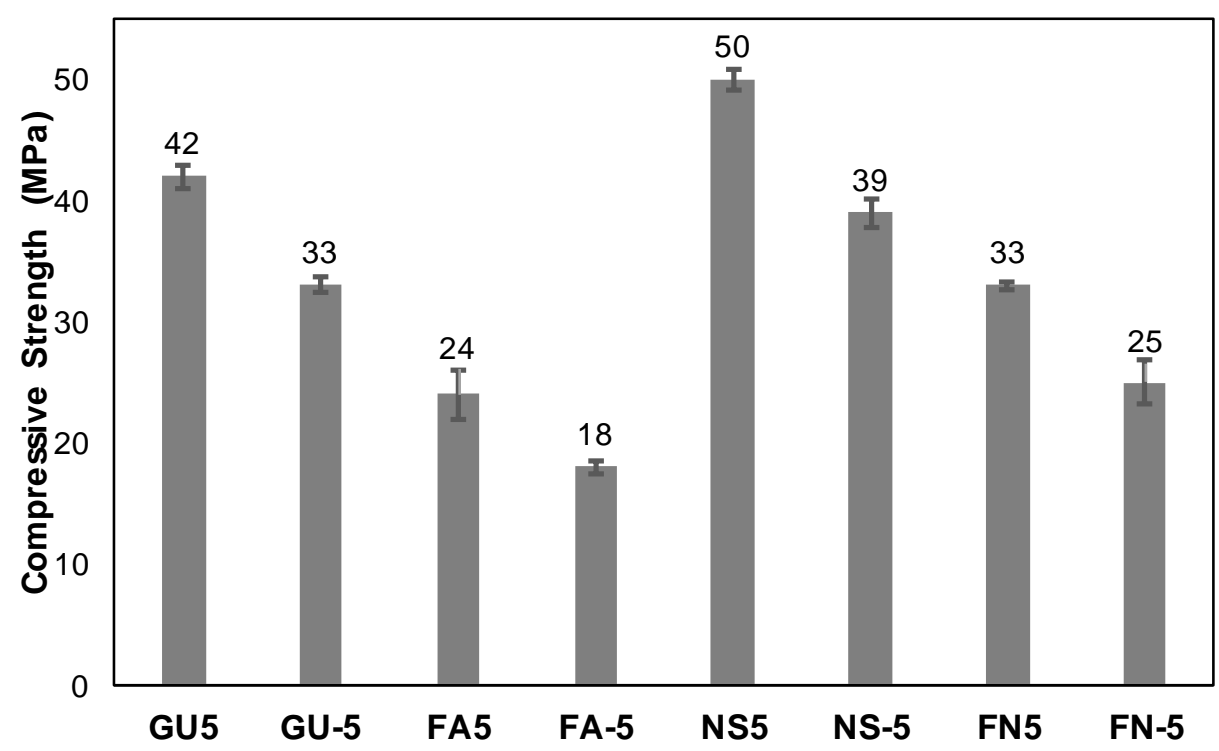

Figure 3: Compressive strength of concrete cured at $-5^{\circ} \mathrm{C}$ and $\left(5 /-5^{\circ} \mathrm{C}\right)$ regimes.

(Note: error bars represent standard deviation)

Concrete mixtures that were cured in the cyclic regime $\left(5 /-5^{\circ} \mathrm{C}\right)$ achieved higher strength than that of corresponding mixtures that cured in the constant freezing temperature $\left(-5^{\circ} \mathrm{C}\right)$. For instance, mixture FA5 had 33\% higher strength than that of FA-5, which had a value of $24 \mathrm{MPa}$. Conforming to the well-documented effect of curing temperature on development of concrete strength (Neville, 2011), the constantly freezing temperature led to decelerating the degree of hydration, resulting in lower strength at 28 days. However, the level of hydration and strength were improved in the cyclic regime, which involved $33 \%$ of the curing time at $5^{\circ} \mathrm{C}$.

As expected, the results showed the adverse effect of the incorporation of $25 \%$ fly ash on the development of concrete strength in both curing regimes. For instance, the strength of mixture FA5 was reduced by $43 \%$ relative the reference mixture GU5. This limitation has been stipulated in ACI 306R (2016), which does not recommend using slowly reactive SCM such as fly ash in concrete cast under cold weather, to avoid delays in strength development of concrete at an adequate level which is required to resist severe weather conditions such as freezing-thawing cycles. 
The mixtures containing nano-silica yielded higher strength values than that of corresponding mixtures without nano-silica, as shown in Figure 3. For example, the incorporation of nano-silica in mixture GU to develop mixture NS enhanced the 28 days strengths by 19 and $18 \%$ for both the cyclic and constant curing regimes, respectively. Moreover, the presence of nano-silica enhanced the strength development in fly ash mixtures. The 28 day strength of mixtures FN5 and FN-5 increased by $38 \%$ and $39 \%$, respectively compared to the corresponding mixtures FA5 and FA-5.

The strength range of nano-modified and nano-modified fly ash mixtures varied between 25 to $50 \mathrm{MPa}$, which complies with the strength requirements, 20 to $40 \mathrm{MPa}$, of normal concrete for many infrastructural applications such as concrete pavements, buildings, bridges and sidewalks (MacGregor et al., 1997). At normal temperatures, previous studies concluded that this improvement in strength can be attributed to multiple mechanisms such as the nucleation, pozzolanic, water reduction, and filler effects of nano-silica aggregates in cementitious systems, resulting in additional calcium silicate hydrate $(\mathrm{C}-\mathrm{S}-\mathrm{H})$ gel with higher stiffness and denser microstructure (Said et al., 2012; Hou et al., 2013). Again, the aforementioned strength results verified that the presence of CNAI in these mixtures maintained the functionality of nano-silica at a freezing temperature.

\section{Mercury Intrusion Porosimetry (MIP)}

The MIP results are presented in Table 4, and the trends are in agreement with the compressive strength results. Although the apparent porosity values were not markedly affected by the curing regime, the threshold pore diameter and proportion of micropores (less than $0.1 \mu \mathrm{m}$ ) were significantly affected. Generally, concrete mixtures which were cured in the cyclic temperature achieved lower threshold pore diameters and proportions of micro-pores than that of corresponding mixtures which were constantly cured at $-5^{\circ} \mathrm{C}$. For instance, specimens from mixture FN5 had $75 \%$ lower threshold pore diameter and $83 \%$ higher proportion of micro-pores, respectively than that of specimens from mixture FN-5. This verified the aforementioned effect of curing regime on the evolution of concrete microstructure and strength. The MIP results showed the adverse effect of fly ash inclusion on microstructural development. For instance, the incorporation of $25 \%$ fly ash in mixture GU-5 to produce mixture FA-5 increased concrete porosity and threshold pore diameter as well as reducing the proportion of micro-pores by $23 \%, 60 \%$ and $18 \%$, respectively. This coarse microstructure explains the relatively low strength values of mixtures incorporating fly ash only.

MIP results of nano-modified and nano-modified fly ash mixtures substantiated the aforementioned positive effects of nano-silica on improving concrete microstructure regardless of the adopted curing regime. For instance, incorporating nano-silica in mixture GU5 to develop mixture NS5 decreased the 28 days porosity and threshold pore diameter by 15 and 77\%, respectively; correspondingly, the proportion of micropores increased by $11 \%$. In addition, the presence of nano-silica significantly enhanced the development of microstructure of fly ash mixtures. For instance, the porosity and threshold pore diameter of FN5 decreased by $10 \%$ and $75 \%$, respectively with high 
increase in the proportion of micro-pores (45\%) compared to that of mixture FA5. These trends reflected that the nano-modified mixtures had refined pore structure, which explains their improved compressive strength.

Table 4-Summary of MIP test results

\begin{tabular}{c|c|c|c}
\hline $\begin{array}{c}\text { Mixture } \\
\text { ID }\end{array}$ & $\begin{array}{c}\text { Apparent Total } \\
\text { Porosity }(\%)\end{array}$ & $\begin{array}{c}\text { Threshold Pore } \\
\text { Diameter }(\mu \mathrm{m})\end{array}$ & $\begin{array}{c}\text { Proportion of Micro- } \\
\text { Pores }(<0.1 \mu \mathrm{m})\end{array}$ \\
\hline GU5 & 14.2 & 0.3 & 58 \\
\hline GU-5 & 14.6 & 0.5 & 36.5 \\
\hline FA5 & 17.9 & 0.4 & 52 \\
\hline FA-5 & 18 & 0.8 & 30 \\
\hline NS5 & 12.1 & 0.07 & 64.5 \\
\hline NS-5 & 12 & 0.3 & 41.5 \\
\hline FN5 & 16.1 & 0.1 & 75.4 \\
\hline FN-5 & 16.7 & 0.4 & 41 \\
\hline
\end{tabular}

\section{Scanning Electron Microscopy}

BSEM on thin sections prepared from the eight mixtures was performed to compliment the trends obtained from the bulk tests. In addition, EDX analysis was performed on several points within the ITZ to calculate the calcium-to-silicate ratio $(C / S)$ of C-S-H. It was reported that the $C / S$ of secondary/pozzolanic and conventional C-S$\mathrm{H}$ is approximately 1.1 and 1.7, respectively (Detwiler and Bhattacharja, 1996).

Generally, the GU, fly ash and nano-modified mixtures had dissimilar microstructure [Figures 4(a)-(h)]. CWAS such as calcium nitrite and calcium nitrate, that contain the same cations as $\beta-\mathrm{C}_{2} \mathrm{~S}$ and $\mathrm{C}_{3} \mathrm{~S}$ in cement, can accelerate the hydration process due to the nucleating action of such ions resulting in intensification of the hydrate crystallization processes and improvement in concrete microstructure and strength at early-age (Ratinov and Rozenberg, 1996). The incorporation of fly ash and nano-silica significantly affected the microstructural morphology of concrete. For instance, GU mixtures (GU-5 and GU5) had an intermediate microstructure in the ITZ, where the $C / S$ varied between 1.65 to 2.1 with an average of 1.9 [Figures 4(a), (c)]. The incorporation of $25 \%$ fly ash (FA-5 and FA5) produced coarse microstructure and interconnected micro-cracks in the ITZ; the $C / S$ in the ITZ varied from 1.8 up to 2.4 with an average of 2.1 [Figures $4(\mathbf{e}),(\mathbf{g})$ ]. These features indicate an insufficient hydration development conforming to the previously described strength values and pore structure parameters. 
Comparatively, the incorporation of nano-silica with GU (NS-5 and NS5) produced a homogenous matrix and densified microstructure with $C / S$ in the ITZ of 1.1 [Figures $\mathbf{4 ( b ) , ( d ) ] , ~ w h i c h ~ i n d i c a t e d ~ e f f i c i e n t ~ p o z z o l a n i c ~ a c t i v i t y ~}$ and densification of ITZ by 



Figure 4: BSEM micrographs for thin sections from mixtures: (a) GU-5, (b) NS-5 , (c) GU5, (d) NS5, (e) FA-5, (f) FN-5, (g) FA5, (h) FN5. 
deposition of secondary C-S-H. In addition, in comparison to the fly ash mixtures (FA-5 and FA5), the nano-modified fly ash mixture (FN-5 and FN5) had noticeable improvement in the degree of hydration and refinement in the ITZ and hydrated paste due to the synergistic effects of nano-silica and

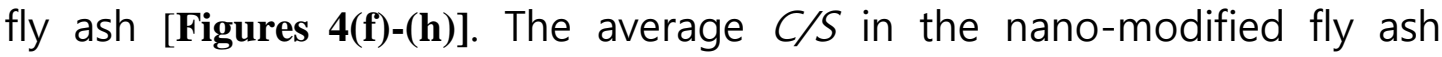
mixtures were around 1.4 .

\section{CONCLUSIONS}

Considering the materials, mixture proportions, mixing/curing regimes and tests performed in this study, the following conclusions can be drawn:

- The incorporation of $25 \%$ fly ash prolonged the setting time while the addition of $4 \%$ nano-silica shortened the hardening time of concrete cast at $-5^{\circ} \mathrm{C}$. The incorporation of nano-silica particles significantly accelerated the hydration and solidification processes, as the existence of CNAI was effective at depressing the freezing point of liquid phases, which maintained the functionality of nanosilica at sub-zero temperatures.

- The strength range of nano-modified and nano-modified fly ash mixtures that were cast and cured under both freezing $\left(-5^{\circ} \mathrm{C}\right)$ and cyclic $\left(5 /-5^{\circ} \mathrm{C}\right)$ regimes varied between 25 to $50 \mathrm{MPa}$. These values comply with the strength requirements of normal concrete for many infrastructural applications.

- The MIP and BSEM trends showed that the incorporation of $4 \%$ nano-silica into concrete significantly refined and densified the pore structure of concrete, which was cured at cold temperatures.

- The overall results from this study suggest that nano-modified concrete mixtures can achieve satisfactory performance in terms of strength and durability under low and freezing temperature conditions in the field. Hence, they may present a viable option to extend the construction season in cold regions, such as North America and Europe, during late fall and early spring periods, without the need for heating and insulation practices.

\section{ACKNOWLEDGEMENTS}

The authors highly appreciate the financial support from Natural Sciences and Engineering Research Council of Canada (NSERC RGPIN/4024-2014) and University of Manitoba Graduate Fellowship and GETS programs. The IKO 
Construction Materials Testing Facility at the University of Manitoba in which these experiments were conducted has been instrumental to this research.

\section{REFERENCES}

ACI-Committee-306. (2016). "Guide to cold weather concreting." ACI 306R, American Concrete Institute, Farmington Hills, Michigan, USA.

ASTM C260/C260M. (2016). "Standard specification for air-entraining admixtures for concrete." ASTM International, West Conshohocken, Pennsylvania, USA.

ASTM C39/C39M. (2018). "Standard test method for compressive strength of cylindrical concrete specimens." ASTM International, West Conshohocken, Pennsylvania, USA.

ASTM C403/C403M. (2016). "Standard test method for time of setting of concrete mixtures by penetration resistance." ASTM International, West Conshohocken, Pennsylvania, USA.

ASTM C494 / C494M. (2015). "Standard specification for chemical admixtures for concrete" ASTM International, West Conshohocken, Pennsylvania, USA.

Barna, L. A., Seman, P. M., and Korhonen, C. J. (2011). "Energy-efficient approach to cold-weather concreting." Journal of Materials in Civil Engineering, 23(11), $1544-1551$.

CAN/CSA-A3001. (2013). "Cementitious materials for use in concrete." Canadian Standards Association, Mississauga, ON, Canada.

CSA-A23.1/A23.2. (2014). "Concrete materials and methods of concrete construction/ test methods and standard practices for concrete." Canadian Standard Association (CSA), Mississauga, Ontario, Canada.

Detwiler, R. J., Bhatty, J. I., \& Battacharja, S. (1996). "Supplementary cementing materials for use in blended cements." Portland Cement Association, Skokie, IL, $103 \mathrm{p}$.

Ghazy, A., Bassuoni, M. T., and Shalaby, A. (2016). "Nano-modified fly ash concrete: A Repair Option for Concrete Pavements." ACI Materials Journal, 113(2), 231242.

Haruehansapong, S., Pulngern, T., and Chucheepsakul, S. (2014). "Effect of the particle size of nanosilica on the compressive strength and the optimum replacement content of cement mortar containing nano-SiO2." Construction and Building Materials, 50, 471-477.

Hou, P., Kawashima, S., Kong, D., Corr, D. J., Qian, J., and Shah, S. P. (2013). "Modification effects of colloidal nanoSiO2 on cement hydration and its gel property." Composites Part B: Engineering, 45(1), 440-448.

Karagöl, F., Demirboğa, R., Kaygusuz, M. A., Yadollahi, M. M., and Polat, R. (2013). "The influence of calcium nitrate as antifreeze admixture on the compressive strength of concrete exposed to low temperatures." Cold Regions Science and Technology, 89, 30-35.

MacGregor, J. G., Wight, J. K., Teng, S., and Irawan, P. (1997). "Reinforced concrete: Mechanics and design" (Vol. 3). Upper Saddle River, NJ: Prentice Hall.

Neville, A. M. (2011). "Properties of concrete." Prentice Hall, London, UK. 
Polat, R. (2016). "The effect of antifreeze additives on fresh concrete subjected to freezing and thawing cycles." Cold Regions Science and Technology, 127, 10-17.

Ratinov, V. B., and Rozenberg, T. I. (1996). "Antifreezing admixtures." In Concrete Admixtures Handbook (Second Edition).

Said, A. M., Zeidan, M. S., Bassuoni, M. T., and Tian, Y. (2012). "Properties of concrete incorporating nano-silica." Construction and Building Materials, 36, 838-844.

Senff, L., Labrincha, J. A., Ferreira, V. M., Hotza, D., and Repette, W. L. (2009). "Effect of nano-silica on rheology and fresh properties of cement pastes and mortars." Construction and Building Materials, 23(7), 2487-2491.

Wesche, K. (2014). "Fly ash in concrete: properties and performance." CRC Press. 